\title{
Some Tentative Proposals to the Current Reform of Chinese College English Teaching on the Basis of Needs Analysis
}

\author{
Shi Jian ${ }^{1}$ \\ ${ }^{1}$ College of Humanities and Foreign Languages, Xi' an University of Science and Technology, China \\ Correspondence: Shi Jian, College of Humanities and Foreign Languages, Xi'an University of Science and \\ Technology, Lintong District, Xi'an Shaanxi 710600, China. E-mail: smith168@126.com
}

Received: April 6, 2013 Accepted: April 20, 2013 Online Published: June 3, 2013

doi:10.5539/elt.v6n7p79 URL: http://dx.doi.org/10.5539/elt.v6n7p79

\begin{abstract}
Under the circumstances of economic globalization and educational internationalization as well as against the background of the improved requirements in the new High School English Syllabus (HSES), the Chinese college English teaching (CET) nowadays is confronted with great pressure and unprecedented challenges with the decrease of school-aged population and increase of quality competition in higher education. Based upon the needs analysis(NA) of students' progress in English proficiency, the social development and the growth in the discipline of English itself, this paper submits some tentative suggestions or proposals as regards the appropriate English teaching models at tertiary institutions in hope to do a bit of good to the current CET reform in China.
\end{abstract}

Keywords: NA, CET reform, CET models, proposals and suggestions for CET

\section{Introduction of the Research Background}

In the context of economic globalization, English, as a lingua franca, is the most effective and frequently-used medium for people to communicate and exchange information across the planet. With the deepening of reform and opening up in China, more and more transnational corporations will enter the Chinese mainland and a rising number of Chinese companies will move towards the world as well. They require their personnel not merely possessing the fundamental capabilities in English but also acquiring the occupation-particular English competence. According to Cai Jigang (2012), such employing units as firms, enterprises, joint ventures etc. call for certain professional English abilities related to their jobs and majors rather than solely satisfy the general literacy in English basic skills from the university graduates. Therefore, recent years has witnessed the great popularity of BEC (Business English Certificate), TOPE (Test of Professional English), TOEIC (testing of English for International Communication), and so on and so forth.

Educational internationalization, as Cai Jigang (2012a) mentions, is the sure result of economic globalization, or the incarnation of globalization in the aspect of education (Cai Jigang, 2012b).The Outline of National Middle/Long Term Education Reform and Development Plan encourages all type of education to carry out international communication and cooperation. In terms of higher education, it is not only shown in the collaboration with alien counterparts in running schools, but in the promotion of international courses as well. For example, The University of Nottingham Ningbo China was initiated in 2005, The Xi'an Jiaotong - Liverpool University was founded in 2006, and The NYU Shanghai came into existence in 2012, all of which have landmark significance in the Chinese education history. And also, The Confucius Institute has branched out throughout the globe to spread Chinese and its culture. In addition, many a world-famous university, like Yale University and Harvard University, uploads some open class videos by renowned professors to the Internet for promotion, which is convenient access from every corner of the Earth free of charge. Hence, the tide of educational internationalization asks for a higher demand in English proficiency. Further, more than $70 \%$ of the world's scientists read English and 90\% of all information in the world's electronic retrieval systems is stored in English (extracted from English Teaching Forum, Jan. 2000). Supposing one wants to genuinely understand his professional literature in the present information age, the good command of English is a must. Meanwhile, English increasingly serves as a main language in spreading academic knowledge (Hyland, K., \& Hamp-Lyons, 2002). Researchers are obligate to publish their findings in the international journals of certain fields by employing authentic academic English, which is why scholars come up with a new conception: EAPP (English for Academic Publishing Purpose). On the other hand, a growing number of Chinese University graduates intend 
to go overseas for further study and they have to reach a certain score in TOEFL (Testing of English as a Foreign Language), IELTS (International English Language Testing System), WSK (Waiyu Shuiping Kaoshi), and PETS (Public English Test System), which are the acknowledged tests in measuring one's English level at home and abroad. Besides, those who want to earn a degree of MBA (Master of Business Administration) are obliged to take GMAT (Graduate Management Admission Test) or others who are eager to be postgraduates (master or doctor candidates) in USA have to sit for GRE (Graduate Record Examination), which both pose much higher expectations for their English achievements.

What's more, with the comprehensive application of the new HSES, the requirements for high school graduates in China is now similar or approximate to that for college graduates (as is stipulated by College English curriculum requirements(provisional regulations),2007). In other words, the whole college English curriculums have been transplanted into high school English teaching. That's to say, such linguistic phenomena and communicative functions as some words and expressions, grammatical points and syntactic patterns, which should have been taught in CET, has been transferred into the high school English course books under the new HSES ,which put forward the improved requirements for high school English. This naturally raises a series of questions for us: what's the content and direction of CET? (Cai Jigang, 2004) Should we still orient the CET as EGP (English for General Purposes) or General English (GE)? EGP/GE teaching will definitely bring forth slack in CET (Dai Weidong, 2001) and lead to the problem of time consumption and inefficiency (Cai Jigang, 2010a). Should we position the CET as ESP (English for Specific Purposes) or a combination of EGP/GE and ESP? Traditionally, ESP consists of both EAP (English for Academic Purposes) and EOP (English for Occupational Purposes). How do we strike a balance between EAP and EOP in our routine CET? Should we anchor the CET as or BE (Bilingual Education)? It can be still doubtful whether BE is applicable to the CET in every category of Chinese university.

Last but not least, quoted from Chen Wei\& Gu Xin (2010), with the fall of Chinese birthrate, the year of 2008 saw an inflexion point in school-aged population for tertiary education, which began to dwindle on a small scale, and this inclination is to last till 2025. The drop in the student source threatens the majority of enrollment-expanded higher education institutions, who will certainly seize the limited student source and increase their enrollment rate via fierce quality competition by providing better teaching services. As is known to all, CET, a basic compulsory course in universities of all types at present, plays a prominent and essential part in the improvement of the whole teaching quality that can create the good reputation or image of the university itself among the university candidates (applicants). So how to develop a suitable CET curriculum to satiate the college English Learning needs of students with diversified backgrounds becomes a thorny question for most of Chinese universities when designing their characteristic course modules.

Take what is discussed above into account, the contemporary CET in China needs to be reformed immediately to adjust itself to the ever-changing conditions and we, the CET practitioners, should base the CET revolution on the rational NA of students, society and the discipline of English itself.

\section{NA of Chinese CET}

\subsection{Overview about the NA Theory}

NA, there being no consensus about its definition (or analysis model) among scholars, retains still an umbrella terminology. According to Chen Bingbing (2009), NA is principally applied to ESP in the field of foreign language education and the term was firstly advanced by Michael West in the literature in the 1920s. NA is to understand the requirements of language learners for language learning and arrange the courses in accordance with their needs. Richards (1984) classifies necessity into objective and subjective one, the former being referred to as needs from the perspective of society while the latter as wants as far as students are concerned, and there usually exists a large discrepancy between them. Berwick (1989) divides the needs into the predetermined needs and realized needs. The predetermined needs are defined as the requirements established by educators judging by others' learning experiences while the realized ones refer to the learner's own need or wish. Brindley (1989) and Robinson (1991) mention the concept of the objective and subjective needs. The objective needs are interpreted as the learner's biographical data like age, gender, nationality, marital status, educational background, the language courses having been already learned, current language proficiency, difficulties in learning a foreign language and the present or planned occupation. And the subjective one are explained to be the learner's cognitive and emotive needs in language learning such as self-confidence, attitude and anticipation etc. $\mathrm{H}$. G. Widdowson (1983) points out that the most appropriate definition of needs is goal-oriented needs and he also indicates that needs refer to the student's requirement of current learning and future work.

At present, research about NA model abroad is quite developed and full-grown which totally has experienced 4 
phases of evolvement: Munby's TSA (Target Situation Analysis), aiming to make an analysis of the target communicative competence (Munby, 1978); Allwright's PSA (Present Situation Analysis), concerning the deficiency analysis between what the learners have already known and what they need under the circumstances of target linguistic performance (Allwright, R. 1982); Hutchinson and Waters' analysis model, adopting the learning-centered path to conduct needs analysis (Hutchinson \& Waters, 1987), in which Learner needs are approached from the two directions of target needs and learning needs (Chamnong Kaewpet, 2009). Dudley Evans and St John's analysis model, employing the means analysis and ecological approach (Dudley-Evans \& St. John, 1998), which analyzes the students' learning of language skills in great detail, and gets the learners' personal and occupational information connected with target scene and learning environment. Reducing greatly the randomness in course design and implementation, Dudley Evans and St John's analysis model turns out to be the latest and the most perfect model of need analysis in the areas of EFL (English as a Foreign Language), ESL (English as a Second Language) and SLA (Second Language Acquisition).

The paper, mainly following the Dudley Evans and St John's analysis model, attempts to evaluate the already-altered situations and college English learning needs from the angles of students, social development and the growth in the discipline of English itself.

\subsection{Students' $N A$}

Entering the 21st century, English teaching in primary and high schools has been undergoing dramatic curriculum reforms in China (Wen Qiufang, 2012). Due to the drastic change in the teaching requirements and the comprehensive enforcement of the new HSES, the vocabulary in the new high school English course books has been enormously enlarged and the high school graduates are asked to grasp as many English words as 3500 . Apart from the broadening of the vocabulary size, the new HSES has almost covered all the English grammatical items and involved nearly 70 functional conceptions (Wen Qiufang, 2012). That's to say, the over ten years of English learning from elementary school to High school has incorporated adequate knowledge as to the English language itself. More and more freshmen can start to learn from the band 2 even band 3 of the college English and what is even better is that some first-year students from some key universities have laid such a solid foundation in their mastery of the English language that they have already arrived at the general demand for college graduates (Band 4 of college English). Namely, some key university students can pass the CET4 (College English Test Band 4) at the first semester of college. This indicates that the continuation of GE/EGP teaching in university will not fulfill the expectations of vast majority of college students. If we go on to do so, it is invariably to lead to the repetitive labor and low efficiency in CET and will surly slacken students' enthusiasm in English learning.

Generally speaking, English proficiency includes proficiency in five language domains: grammar, listening, speaking, reading and writing. Greatly influenced by Gaokao (Entrance Examination to University (EEU)), High school graduate's English proficiency level is assessed more by grammar, vocabulary and structure, reading and writing than listening and speaking. CET, however, is evaluated by more pragmatic language skills which undoubtedly involve the above-mentioned five aspects of proficiency, but it lays more stress on the practical and useful application of English. Adduced from a survey of 6625 freshmen in 36 universities from 21 provinces or municipalities in China, which was conducted by Cai Jigang in November, 2009, what the newcomers in college want to improve most is the listening ability (70.2\%) and speaking skill (86.2\%) in English and the English proficiency correlated with their majors or future jobs ranks three $(52.9 \%)$ in their priorities. This shows that most of the university English learners are keen to enhance their audial as well as oral capabilities in English and more than half of them aspire to take the ESP courses connected with their majors to strengthen the practical abilities in utilizing the English tool in their coming careers.

Owing to the uneven distribution of foreign language faculties and teaching resources, as Wen Qiufang (2012) said, there lies obvious differentiation in teaching quality between urban and rural areas as well as across the variant regions. So the college freshmen's English level takes on the tendency of polarization and the students' needs difference has been augmented than ever before. So how to handle the regional differences regarding English language proficiency levels among college freshmen grows to be a headache for the university administration and the college English department.

\subsection{Social Development $N A$}

The entry of more transnational corporations and foreign financial setups, the frequency of holding international conference annually, the international tourist arrivals per year and the population proportion of foreign nationality will keep roaring with the Chinese Opening up going deep. These international organizations, transnational enterprises, cross-culture communications and international meetings are in great demand of 
qualified international talents, who not only should excel in their expertise but command good English as well to spread knowledge, exchange information and create material and spiritual wealth.

As the Chinese comprehensive national power continues to rise, more and more domestic companies and institutions will go abroad to seek opportunities for their further development, which requests quite a number of staff who are well-trained both in their own professions and in the operational skills of English. Advanced by Dong Wei (2010), the gap of high-end English talents inclines to be widened instead of being bridged. So Wen Qiufang (2012) puts forward, China now needs a large number of intellectuals who can negotiate business and sign contracts in English with their foreign associates and a lot of high-grade tourism management talents who are rather familiar with the target country's culture and language.

With the in-depth opening, such areas as science \& education, medicine \& health, culture \& sports etc. will involve and multiply their manifold contact and communication with their foreign peers. Let's take the fields of education and scientific research as an example, China needs to cooperate and compete with other countries. Whether college students pursue their overseas studying or the researchers in China and other countries collaborate on some projects, English serves as a good means. When Chinese scholars retrieve and read their profound subject-specific literature, their English attainments will help a lot. Especially when some scientists or researchers publish their findings in some world-famous journals, their English writing proficiency will also play an important part.

\subsection{Disciplinary Growth NA}

Based on Wen Qiufang (2012), teaching English as a Foreign Language (EFL) has long been practiced in the world for more than a hundred years and we usually adopt the native speakers' English as our teaching content and judge the failure or success of learning by whether we acquire the perfect native speakers' competence and performance of the English language. Under the milieus of globalization, however, English has become a lingua franca and we may deal with people from English-speaking countries but more with non-native speakers of English. Hence, many scholars advise we should substitute English as a Lingua Franca (ELF) for EFL.

In contrast to EFL, the terminal goal of ELF is not to acquire the native-like competence of English but to raise the extent of comprehension between or among the non-native English speakers while communicating with each other or one another, which can tolerate the linguistic flaws like grammatical errors, pronunciation with local accent, slip of tongues etc. instead of the pursuit of the ideal linguistic output. Thereby, in our daily teaching of ELF, we are suggested to focus on the expressiveness of our thoughts in English to achieve the communicative functions rather than overemphasizing the $100 \%$ correctness of the linguistic forms. Otherwise, we seem to attend trifles but neglect essentials in our CET routines. Admittedly, quite different from the scholarly publications which seek for the accurate definitions, precise classifications and rigid deductions etc. by employing faultless and flawless English jargons, the ELF utilized in our daily life and routine work can endure some defects or deficiencies such as local accent and self-repair in spoken contact and inappropriate words for certain registers or wrong collocations and unacceptable expressions with slightly different connotations (infelicitous dictions) in written communications when the communicative functions are not seriously impeded or distorted.

\section{Models of CET in China}

\subsection{Regard CET as EGP/GE}

Presently, most Chinese Universities still regard CET as a fundamental compulsory course to teach EGP or GE, which is the traditional teaching model having no clear distinction with that manipulated in high school. CET, as a continuation of English teaching in primary and high school, still adheres to the principle of fostering the basic language skills (grammar, listening, speaking, reading, writing and translating).

Certainly, EGP/GE plays a crucial role in consolidating college students' linguistic foundations. Nonetheless, since the joint-track or even the partly overlapping between the new HSES and the traditional CET curriculum after the High school English course reformed, High school graduates have learned almost all the English grammatical items and obtained a great many English words, which makes the EGP/GE in CET repetitive to some degree. "How good is your English" is a good and never-ending question for every non-native English learner because of the bulk of vocabulary and the boundlessly diversified usages of the English language. That's to say, EGP/GE learning is a lifelong business for those who employ English in their daily life and calling.

\subsection{Consider CET as ESP}

Hutchinson \&Waters (1987) grouped CET as GE, centering on the English grammar and vocabulary to train learners' general literacy and ESP, aiming to teach learners English fused with certain fields or subjects. ESP is 
conventionally looked at as English for Science and Technology (EST), which is still thus named and taught in some Chinese universities recently. Depending on the dissimilar objectives, ESP is further classified into EAP (English for Academic Purposes), ESAP (English for Specific Academic Purposes) and EOP (English for Occupational Purposes).

The essence of ESP lies in the fact that we should shift from 'learning English' to 'learning in English' (Zhang Wenyou, 2001). In other words, ESP ought to make CET turn from the pure language learning to Content-Based Instruction (CBI). Many Chinese experts and scholars in the sphere of English education who no longer view college English as part of general education courses or compulsory courses advocate the ESP model in CET, which is listed as follows: Xu Guozhang(1986) maintains, high school students study EGP/GE, university students learn academics-divided English, the arts student attending humanistic English while science and engineering students taking popular science knowledge English, and postgraduates acquire specialized English; Liu Runqing (1996) predicts that the tremendous modification in the future CET may not be the pure language learning any more and CET will steadily combine with certain specialized knowledge or integrate with another disciplinary learning. ESP will be the major trend of CET in the 21st century; Qin Xiubai (2003) suggests, in the long run, the mainstream of Chinese CET should adopt the ESP modal. He further recommends that freshmen and sophomores should learn EAP and juniors and seniors should study ESAP combined with their majors; Lu Jianming (2010) proposes, in view of the repetition among the English teaching in primary school, high school and university, we should reorient the English education in those three stages; Yang Huizhong (2010) holds, what the many large-scale social investigations about the English learning needs analysis reveals the chief goal of CET is to deem English as communicative tool to gain occupational information or output their professional ideas, which manifests CET is ESP by nature. English teaching in elementary and intermediate education should concentrate more time and efforts on the solid foundations while the higher education should place emphasis on academic English (ESAP) or ESP.

\subsection{Treat CET as BE}

$\mathrm{BE}$, according to the definition given by Longman Dictionary of Language Teaching and Applied Linguistics (third edition),signifies the use of a second or foreign language in school for the teaching of content subjects, which is the narrow sense of BE. Broadly speaking, however, BE means the school education by using two languages at the same time. BE programs, specified by Baidu (an Internet search engine), may be of different types and include:

a) The use of a single school language which is not the child's home language. This is sometimes called an immersion program.

b) The use of the child's home language when the child enters school but later a gradual change to the use of the school language for teaching some subjects and the home language for teaching others. This is sometimes called maintenance BE.

c) The partial or total use of the child's home language when the child enters school and a later change to the use of the school language only. This is sometimes called transitional bilingual education.

Applying arbitrarily the aforesaid definition (c), the Chinese BE class in university substantially denotes the class teaching which firstly takes on the combination of Chinese and a foreign language (chiefly English) as the working language and then gradually employs only English to a non-linguistic subject teaching (as the narrow sense of BE formulates), a new teaching modal which allows the learners to pick up both the linguistic and the academic knowledge simultaneously.

In response to the call from Higher education department of China education ministry, lots of universities attempt to open some BE classes for some specialized course English, which introduces the authentic English-version textbooks and trains some experienced specialized course teachers. But whether or not the CET should be replaced by BE completely remains a question. What kind of college is suitable for BE or what level of English proficiency is a requisite for students to attend BE class are the extremely urgent problems worth our trying to find appropriate solutions to as for Chinese existing CET reform.

\subsection{The Relations among EGP, ESP and BE}

Just as He Ye (2012) advocates, BE is established on the basis of foreign language teaching and lifts it to the stratum of the application of the linguistic knowledge into the teaching practice of the specialized courses like mathematics ,physics and chemistry etc. BE is the development and stretching of foreign language learning during the course of the specialized discipline teaching and it functions as a brand-new access to impart the disciplinary knowledge using English as an instrument. ESP bases itself on EGP and is the expansion and 
extension of EGP. ESP and EGP have their own precedence respectively, EGP giving preference to language while ESP emphasizing the aspect of peculiar subject knowledge. Both ESP and BE concern the foreign language teaching, but the former falls into the category of language education while the latter belongs to a kind of working language(tool or instrument ) to organize and conduct the specialized course teaching.

EGP/GE, ESP and BE represent the three developing stages in CET and it constitutes a linear relation between EGP/GE and ESP as well as between ESP and BE. ESP, on the ground of EGP/GE, is the linguistically preparatory step for BE. He Ye (2012) summarizes, it is continuum from EGP/GE to ESP and to BE, a continuous process from the language teaching (both EGP\GE and ESP) to the technique or way of teaching specialized course (BE).

\section{Tentative Suggestions and Proposals to the Reform of Prevailing Chinese CET}

China has more than 2400 universities or colleges of all types presently (In the light of the statistics of China Education Ministry in 2012, there are 844 undergraduate academies, 1288 vocational and junior colleges and 298 independent colleges), which are developed unevenly in terms of whether the students' English foundations or their teaching resources. In consideration of the above-mentioned NA from the perspectives of student, society and the English discipline itself, some preliminary CET modals are submitted in accordance with the categorization of Chinese universities into the first-class university (all the key universities affiliated to China education ministry such as Tsinghua University, Peiking University, Fudan University etc.), the second-class university (all the university attached to the provincial education department) and the third sort of the independent college of the junior/vocational college(all the colleges subordinate to some universities or local education administrations). Meanwhile, with regard to the questions presented in the section one of this paper, some speculative proposals for the Chinese CET revolution and also as suggestions for the questions are provided as follows, which are designed as course menu for students to choose, wishing they can opt elastically on the footing of their needs as well as interests and they can also earn sufficient credits for their graduation.

\subsection{For the First-Class University CET}

After the selection of the EEU, a vast majority of first-class university students in China have stabilized foundations in their English learning and already reached the general requirements for college graduates, i.e., the college English band 4. We firmly counsel that GE should be offered on the teaching platform for a handful of students weak in English to take as electives. Different ESAPs are arranged in line with the adjacent majors as compulsory course for students to adopt in order for them to familiarize themselves with their major's jargons, syntactic structures and discourse features. Such ESAP courses as engineering English, financial English, and legal English, business English, medical English and English for management are furnished by some well-trained teachers with specially-compiled teaching materials wishing to accelerate their academic powers.

To broaden students' horizons, whether arts, science or engineering students, English as Liberal Education (ELE), desiring to promote the general education with English as the teaching language and English Courses of the Humanities (ECH), intending to introduce and spread the national conditions, literature and culture of the English-speaking countries are given on the university public teaching platform for them to elect freely who have the time and energy apart from the obligatory courses. ELE grants courses like Human and Environment, Panorama of Chinese and Western Culture, and Getting to Know the Universe, the history of western civilization, Greek mythology and the Contrast and Comparison Between Oriental and Occidental Culture etc. and ECH affords courses like British and American Literature Anthology, Western Classic Movie \&TV Appreciation and Cross-Cultural Communication etc.

\subsection{For the Second-Class University CET}

Speaking of the second-class universities in China, things become much more complex due to the great numbers and the severe students' polarization in their English foundations. A College English Placement Test (CEPT) is strongly propounded to be held among freshmen and students are graded by referring to their results in EEU and CEPT. For the lower and intermediate group, they'd better undertake the GE class for at least one year compulsorily and after passing certain English Language Skills Assessment (ELSA), they can skip to the ESP class which is opened for the higher group.

ESP courses are set up in various modules taking heterogeneous majors into consideration to cater for students' varied needs. ESP courses are provided by HongKong University for non-English majors are enumerated here for illustration: speaking skills for architecture students, professional English for arts students, clinical oral English for dental students, professional and technical written communication for engineers, English skills for legal students, professional writing for social work students and so on and so forth (Cai Jigang 2010b). We 
advise that in addition to some ESP courses closely relevant to specific majors like medical English, journalism English and legal English,, such adaptable ESP courses with common characteristics as EST, computer English, engineering English, and literature retrieval and reading etc. should be founded more and more to satisfy most students' needs regardless of their majors.

Something worthy of our attention about the second-class university CET is that students may have the different placements of their own, some favoring the EAP courses while others fancying the EOP classes as we subdivide ESP into EAP and EOP earlier. We conjecture that the upper group students after the gradation can choose either ESP or EOP courses totally dependent upon their personal interest and professional plan or under the guidance of their instructors. In so doing, we can keep a balance between ESP and EOP without fearing going into extremes.

\subsection{For the Independent College and the Junior/Vocational College CET}

As for most of students from the independent college and junior/vocational college, the subject of English is their "soft spot" and CET in the form of GE is still a "big headache" for them. The GE module is mightily recommended for their first two years of English learning in college in order that they can make up for their weaknesses and reinforce their fundamental knowledge in English skills. The EOP courses relative to their occupation orientation are allotted to them in the next two years of college learning, which is similar to the specialized/professional English but somewhat easier than that. By thus doing, CET can proceed for four years nonstop to both reinforce the English foundation and develop the applicable skills for the students of the independent college and the junior/vocational college.

Thinking of the unbalanced development of students' English skills, students from the independent college and the junior/vocational college can prioritize their English skills cultivation based on their career planning without forcing them to nurture the all-round abilities in English. For instance, one who will do more readings in English in their future jobs solely need build up their vocabulary and master the basic grammatical phenomena to analyze complex syntactic constructions. Those who will communicate more face to face with foreigners in their daily work merely need practice their spoken English to articulate fluently in their oral expressions.

\section{Concluding Remarks}

In the new era of the 21st century, great changes have taken place in all aspects of our world. CET in China is subject to harsh transformations to adapt itself to the quick-paced society. The paper, on the basis of NA theory, makes attempts to come up with some suggestions or proposals for the contemporary CET reform via doing an analysis of the altered needs from the dimensions of students' progress in English foundations, social development and the growth in the discipline of English itself. The different module combinations in the course menu for the three levels of universities are the author's speculative measures which only work as advice for reference. CET reform in China is so gigantic a project that not only does it claim the endeavors of the leaders and specialists in English higher education circle but it anticipates all the college English teachers joining hands to contribute their original ideas and wisdom as well.

To some degree, those CET modals advised in this paper sound a bit pragmatically occupation-oriented, which seemingly indicates the utmost goal of CET is to find a job in the end. To be frank, most English learners in China tend to serve English in their diurnal life and work as a tool and they harbor the instrumental motivation to study college English well so they can be more competitive when hunting for jobs in the talent market. But even so, the job-centered inclination is not incompatible to the ultimate purpose of humanistic quality cultivation of CET. As a matter of fact, as Shi Jian (2013) argues, Tool-oriented teaching and quality-centered education are not contradictory to each other; tool-oriented teaching is also a part of humanistic quality education. From the perspective of humanistic education, students can clearly know more about instrumental functions of English language, and then they can find more effective means to use English as a tool. Therefore, the experimental CET curriculum modals suggested above, which displays a little job-driven tendency superficially, not solely can nurture students' English practical competence correlated with their future occupations, but nourish their humanistic qualities as a whole-person education.

\section{References}

Allwright, R. (1982). Perceiving and Pursuing Learner's Needs. In Geddes, \& G. Sturtridge (Eds.), Individualisation (pp. 24-31). Oxford: Modern English Publications.

Baidu the Definition of Bilingual Education. Retrieved April 19, 2013, from
http://baike.baidu.com/view/850705.htm

Berwick, R. (1989). Needs Assessment in Language Programming: From Theory to Practice. In R. Johnson (Ed.), The Second Language Curriculum (pp. 48-62). Cambridge: CUP. 
http://dx.doi.org/10.1017/CBO9781139524520.006

Brindley, G. (1989). The Role of Needs Analysis in Adult ESL Program Design. In R. Johnson (Ed.), The Second Language Curriculum. Cambridge: CUP.

Cai Jigang. (2004). ESP and the Development Direction of CET in China. Foreign Language World, 2004(2), $22-28$.

Cai Jigang. (2010a). Reflection on the Reorientation of CET in China. Foreign Language Teaching and Research, 2010(7), 306-308.

Cai Jigang. (2010b). ELE vs. ESP-- the Orientation of College English. CAFLE, 2010(9), 22-26.

Cai Jigang. (2012a). A Study of the Needs-Analysis-Based ESP Program at the Tertiary Level. Foreign Language Education, 2012(5), 47-50.

Cai Jigang. (2012b). A Study of CET Orientation against the Background of the Internationalization of Higher Education. Journal of Foreign Languages, 2012(1), 69-76.

Chamnong Kaewpet. (2009). A Framework for Investigating Learner Needs: Needs Analysis Extended to Curriculum Development. Electronic Journal of Foreign Language Teaching, 6(2), 209-220.

Chen Wei, \& Gu Xin. (2010). On the Population Policy and the Development of Regular Higher Education. Journal of Higher Education, 2010(3), 12-19.

Chen Bingbing. (2009). The Review of Needs Analysis Research Abroad. Foreign Language Teaching and Research, 2009(3), 125-130.

Dai Weidong. (2001). The Construction of the Streamline ELT System in China. Foreign Language Teaching and Research, 33(5), 322-327.

Dong Wei. (2010). The Talent 'Short Plank' Hinders Chinese Enterprises from Going Abroad. China Youth Daily 2010-7-8.

Dudley-Evans, \& St. John. (1998). Developments in English for Specific Purposes: A Multi-Disciplinary Approach. Cambridge: CUP.

He Ye. (2012). Orientation of College ESP Teaching under Discussion of Learner's Learning Needs. Journal of Nanjing University of Aeronautics and Astronautics (Social Sciences), 2012(9), 92-96.

H.G. Widdowson. (1983). Learning Purpose and Language Use. Oxford: Oxford University Press.

Hutchinson, \& Waters. (1987). English for Specific Purposes--A Learning-centered Approach. Cambridge: CUP.

Hyland, K., \& Hamp-Lyons. (2002). EAP: Issues and Directions. Journal of English for Academic Purposes, 2002(1), 1-12. http://dx.doi.org/10.1016/S1475-1585(02)00002-4

Liu Runqing. (1996). Notes on the Report from “English 2000”. Foreign Language Teaching and Research, $1996(2), 1-8$.

Lu Jianming. (2010). Seminar addresses. China Foreign Language Strategy Forum in 2010 Shanghai: Shanghai International Studies University, 2010.

Munby. (1978). Communicative Syllabus Design. Cambridge: CUP.

Qin Xiubai. (2003). The Nature, Category and Teaching Principles of ESP. Journal of South China University of Technology (Social Science Edition), 2003(12), 79-83.

Richards, J. (1984). Language Curriculum Development. RELC Journal, 1984(15), 1-29. $\mathrm{http}: / / \mathrm{dx}$. doi.org/10.1177/003368828401500101

Robinson, P. (1991). ESP Today: A Practioner's Guide. New York: Prentice Hall.

Shi Jian. (2013). The Integration of Quality-Oriented Education and Instrument-Driven Training in Chinese College English Teaching. English Language Teaching, 6(5), 38-43. http://dx.doi.org/10.5539/elt.v6n5p38

Wen Qiufang. (2012). The Challenges and Strategies Faced with College English from the Perspective of Curriculum Theory. Foreign Language Teaching and Research, 2012(3), 283-292.

Xu Guozhang. (1986). A Feasible Pattern: three-level of English Teaching. Curriculum, Teaching Materials and Teaching Methods, 1986(9), 3-4.

Yang Huizhong. (2010). EAP in China: Review, Status quo and Expectation. China ESP Research Top-Level Forum, Beijing: Beijing International Studies University, 2010. 
Zhang Wenyou. (2001). The Orientation of English Education Reform in Japan. Foreign Language World, $2001(5), 33-36$.

\section{Copyrights}

Copyright for this article is retained by the author(s), with first publication rights granted to the journal.

This is an open-access article distributed under the terms and conditions of the Creative Commons Attribution license (http://creativecommons.org/licenses/by/3.0/). 